\title{
Analisis Peran Konten Instagram Universitas dan Loyalitas Mahasiswa terhadap Peningkatan Reputasi Universitas Kota Batam
}

\author{
Muhammad Ardiansyah \\ Program Studi Sistem Informasi, Universitas Internasional Batam \\ email:muhammad.ardiansyah@uib.ac.id
}

(Received: 7 April 2021/ Accepted: 25 April 2021 / Published Online: 20 Juni 2021)

\begin{abstract}
Abstrak
Suatu universitas dituntut untuk terus meningkatkan reputasinya dan dengan bantuan media sosial universitas dapat meningkatkan reputasinya melalui penyediaan konten dan peningkatan loyalitas melalui media sosial tersebut. Tujuan dari penelitian ini adalah menganalisis besaran pengguna media sosial dikalangan mahasiswa yang belajar pada institusi perguruan tinggi, menganalisis pentingnya penyediaan konten pada media sosial dalam upaya meningkatkan reputasi universitas, menganalisa bagaimana konten sosial media instagram suatu universitas dapat dikatakan baik dalam penyediaan informasi, menganalisis pentingnya loyalitas mahasiswa terhadap reputasi suatu universitas, sebegai pertimbangan suatu universitas dalam mempertimbangkan jenis konten dan interaksi yang akan diberikan kepada mahasiswanya melalui media sosial, untuk mengetahui tingkat loyalitas mahasiswa terhadap universitas. penelitian ini menggunakan metode kuantitatif dengan Konten pada media sosial Instagram universitas dan loyalitas mahasiswa sebagai variabel bebas, serta Reputasi Universitas sebagai variabel terikat. Kuesioner disebarkan secara online menggunakan google form, untuk pengolahan datanya menggunakan aplikasi SPSS. Penelitian ini menggunakan teknik analisis regresi dengan beberapa pengujian yang terdiri dari uji validitas data, uji reliabilitas data, uji normalitas, dan uji korelasi. Sample dalam penelitian ini adalah 395 orang mahasiswa dari universitas di kota Batam. Penelitian ini membuktikan bahwa Konten Media Sosial Universitas memiliki pengaruh terhadap reputasi universitas, dan Loyalitas Mahasiswa juga berpengaruh pada reputasi universitas di lingkungan sosial.
\end{abstract}

Kata kunci: Instagram, Konten Media Sosial, Loyalitas Mahasiswa, Media Sosial, Reputasi Universitas

\begin{abstract}
A university is required to continuously improve its reputation and with the help of social media (SocMed), the university can grow its reputation through providing content and increasing loyalty through SocMed. The purpose of this study is to analyse the number of SocMed users among students at higher-education institutions, the importance of providing SocMed content, Instagram SocMed content can be considered as good in providing information, Student's loyalty toward university's reputation, as a consideration for a university in considering the type of content and interaction that will be carried out to students via SocMed, and to determine the importance of student's loyalty toward university. This study uses quantitative methods with Content on the university's Instagram SocMed and student's loyalty as the independent variables, and the University's reputation as the dependent variable. The questionnaire was distributed online using google form. As for data processing, SPSS-App, and data analyst, using regression with several tests consists of data validitytest, data reliability-test, normality-test, and correlation-test. The samples in this study were 395 students from universities in the city of Batam. This study proves that the University's SocMed Content has an influence on the university's reputation, and Student's Loyalty also affects the university's reputation in the social-environment.
\end{abstract}

Keywords: Instagram, Social Media Content, Social Media, Student Loyality, University Reputation 


\section{PENDAHULUAN}

Teknologi informasi telah dan selalu berkembang dari segala aspek yang ada di kehidupan, baik hal yang sederhana hingga hal-hal yang masif. Perkembangan tersebut memudahkan segala aktivitas manusia sehingga tercapai efektivitas dan efisiensi yang menguntungkan. Menurut (Nuryanto, 2012), Teknologi informasi menghadirkan cara baru dalam melakukan kegiatan seharian manusia. Dimana manusia dapat menikmati segala inovasi yang ada dengan memanfaatkan penciptaan teknologi dalam kurun waktu beberapa dasawarsa ini. Berdasarkan dari hasil penelitian oleh (Santoso, Baihaqi, \& Persada, 2017), yang memiliki kesimpulan bahwa jenis dan waktu postingan sangat berpengaruh terhadap like dan komentar yang diperoleh sehingga dapat dibuktikan bahwa jenis postingan memiliki pengaruh terbesar terhadap online engagement. Akan tetapi masih banyak institusi atau instansi yang belum memanfaatkan teknologi terutama media social dalam peningkatan reputasi atau bahkan meningkatkan Namanya untuk dikenal secara lebih massif, maka dari itu penting bagi suatu instansi atau institusi mengerti pentingnya dalam pemanfaatan teknologi untuk membantu dalam peningkatan reputasi instansi atau institusinya itu sendiri.

Berdasarkan penelitian sebelumnya menyatakan bahwa konten dari postingan yang dibagikan memberikan dampak pada metrics media sosial Instagram dan Facebook diantaranya terlihat dari like dan komentar (Limongi, Santos, \& Almeida, 2016). Konten yang dibegikan memiliki dampak pada keterlibatan secara daring yang terjalin antara pengguna dan penerima pesan pada media sosial dengan diwakili secara like dan komentar yang diterima (Luarn \& Chiu, 2015). Ada pula penelitian yang menyatakan bahwa dampak konten post pada populatitas suatu merek (Vries et al., 2012). Faktor yang mempengaruhi kepopuleran pada postingan dapat dilihat melalui like dan komentar yang didapat (Ryan \& Zabin, 2010). Suatu post dapat dilihat mendapatkan beberapa respon dari konsumen yang diwakili oleh like dan komentar, semakin banyak jumlah komentar dan jumlah like maka dapat dikatakan bahwa postingan tersebut memiliki dampak yang cukup signifikan pada pengguna media sosial lainnya. Semakin banyak respon yang diterima maka hal ini menandakan bahwa merek tersebut dapat menghasilkan hubungan dengan konsumen secara intens dan baik. Selain itu, jumlah komentar dan like yang banyak akan memberikan peluang pada merek untuk lebih dikenal didalam pasar. Berdasarkan penelitian yang dilakukan oleh (Santoso et al., 2017) yang berjudul Pengaruh Konten Post Instagram terhadap Online Engagement: Studi Kasus pada Lima Merek Pakaian Wanita menyatakan bahwa tipe post dan waktu posting (bulan dan hari) memiliki pengaruh signifikan terhadap online engagement (like dan komentar). Tipe post event memiliki pengaruh paling signifikan terhadap like dan komentar.

Loyalitas dari mahasiswa pendidikan tinggi merupakan aspek terpenting untuk keberlanjutan institusi pendidikan tinggi seperti pendidikan tinggi dapat dikatakan dinilai baik dari kualitas pendidikan, guru, kepuasan siswa dan Mahasiswa, dan akhirnya kualitas lulusan yang dihasilkan oleh lembaga pendidikan tinggi. Untuk keberlanjutan lembaga pendidikan tinggi tergantung pada berapa banyak calon siswa yang akan menempuh pendidikan di lembaga tersebut, serta citra lembaga pendidikan tinggi. Dengan demikian pendidikan tinggi harus dapat mengelola hubungan dengan siswa yang masih menjalani studi di institusi tersebut. Dalam penelitian dari (Sartikah, Razati, \& Utama, 2019) menyatakan bahwa pengaruh besar pada loyalitas merek berasal dari media sosial terutama pada dimensi measuring satisfaction dan Brand Loyalty. Maka dari itu dalam membuat media sosial yang baik dapat meningkatkan loyalitas pada suatu merek.

Dalam meningkatan reputasi suatu instansi pendidikan dapat ditingkatkan dengan bantuan sistem informasi baik dari sistem utama ataupun sistem pendukung dalam mendapatkan reputasi yang baik dari lingkungan masyarakat, pemerintah, ataupun industri. Seperti yang dibahas pada penelitian yang berjudul pengaruh Sistem Informasi Manajemen 
dan customer value terhadap reputasi Universitas swasta di Kota Batam yang ditulis oleh (Husda, 2019) hasil dari penelitian ini adalah semakin baik pengelolaan system informasi manajemen suatu perguruan tinggi maka akan semakin meningkat pula penilaian mahasiswanya, begitu juga dengan penilaian mahasiswa untuk reputasi perguruan tingginya. Penelitian yang dilakukan oleh (Apriananta \& Wijaya, 2018) menunjukkan bahwa citra positif Universitas Kristen Satya Wacana, Salatiga (UKSW) sangat dipengaruhi oleh penggunaan media online seperti media sosial. Sebagai universitas yang terdiri dari bervarian etnis dan pencapaian prestasinya, sehingga masyarakat luas dengan mudah terpengaruhi dan terdidik oleh berita yang muncul. Sehingga, secara tidak langsung masyarakat dapat menarik kesimpulan sendiri bahwa perguruan tinggi tersebut unggul, berkualitas, berintegritas dan beradab. Dengan memanfaatkan platform media sosial yang ada, kepercayaan juga terwujud yang berasal dari masyarakat, serta hal ini akan memiliki berdampak bagi peningkatan citra positif instansi Perguruan Tinggi. Dari penjelasan di atas, pada penelitian ini membahas mengenai Analisis Peran Konten Pada Media Sosial Instagram Universitas dan Loyalitas Mahasiswa terhadap Peningkatan Reputasi Universitas di kota Batam. Agar dapat membantu universitas dalam menyediakan konten Instagram yang dapat meningkatkan reputasi serta memaksimalkan loyalitas mahasiswa yang nantinya akan memberikan reputasi yang baik pula dari pihak eksternal universitas.

\section{METODE}

Penelitian ini menggunakan pendekatan kuantitatif dengan Konten pada media social Instagram universitas dan loyalitas mahasiswa sebagai variabel bebas, serta Reputasi Universitas sebagai variabel terikat. Kegiatan penelitian ini ditujukan kepada mahasiswa yang berkuliah pada instansi perguruan tinggi yang berada di kota batam, yang memiliki total populasi 20516 (dua puluh ribu lima ratus enam belas) orang, mahasiswa yang terdiri dari 7456 (tujuh ribu empat ratus lima puluh enam) orang dengan pesebaran sebagai berikut yaitu mahasiswa berasal dari UNRIKA (Universitas Riau Kepulauan), dari universitas putera batam sebanyak 5922 (lima ribu sembilan ratus dua puluh dua) orang, mahasiswa dari universitas internasional batam sebanyakl 3612 (tiga ribu enam ratus dua belas) orang, mahasiswa berasal dari universitas batam sebanyak 2814 (dua ribu delapan ratus empat belas), dan mahasiswa dari Universitas Universal sebanyak 712 (tujuh ratus dua belas) orang. Dari penghitungan dengan menggunakan slovin didapat sampel yang akan dijadikan objek penelitian sebanyak 392 mahasiswa yang mengisi kuesioner untuk penelitian ini. Penggunaan Teknik penghitungan slovin ini menggunakan batas toleransi sebesar 5\% sehingga level of confidence ataupun tingkat akurasinya sebesar $95 \%$.

Penelitian ini menerapkan metode purposive sampling. Menurut (Sugiyono, 2018) Purposive sampling adalah suatu metode yang digunakan teknik pertimpangan dalam menentukan sampel yang akan diteliti. Pertimpangan yang dimaksud disini adalah mahasiswa yang masih aktif belajar disuatu perguruan tinggi yang berkedudukan di kota batam, maka dari itu hanya mahasiswa di kota batam yang dapat menjadi responden dalam penelitian ini. Tahapan pengumpulan data dilakukan dengan cara penyebaran kuesioner (Uska, 2017; Uska \& Wirasasmita, 2018) untuk dengan beberapa pertanyaan yang menggambarkan variabel yang telah dijelaskan di atas. Kuesioner disebarkan secara online dengan menggunakan google form, untuk pengolahan datanya menggunakan aplikasi SPSS. Pada penelitian ini, teknik analsiis data yang digunakan adalah analisis regresi (Munandar, 2017; Sriningsih, Hatidja, \& Prang, 2018) dengan melakukan beberapa pengujian diantara lain: uji validitas data, uji reliabilitas data, uji normalitas, (Febriyanti \& Ismatulloh, 2019; Izzati \& Kuswanto, 2019; Nurbani \& Permana, 2020) dan uji korelasi . 


\section{HASIL DAN PEMBAHASAN \\ Hasil}

Hasil survei yang diterima dari berbagai data dan kajian yang tersedia, maka dilakukan analisa data berdasarkan inti permasalahan dan menguji hipotesis yang telah ditentukan. Variabel yang digunakan yaitu Konten Media Sosial Universitas (KSMU) sebagai variabel bebas, Loyalitas Mahasiswa (LM) sebagai variable bebas, serta Reputasi Universitas (RE) sebagai variable terikat. Dengan pengkodean indikator untuk variabel independen dan dependen sebagai berikut:

1. Konten Sosial Media Universitas (KSMU)

Advantageous Campaign (AC), Relevant Content (RC), Frequently Update Content (FUC), dan Popular Content (PC).

2. Loyalitas Mahasiswa (LM)

Keinginan untuk berinteraksi dengan Universitas (KIU), Keinginan untuk berinteraksi dengan Universitas menggunakan Media Sosial (KIMS), Rasa ingin tahu informasi terbaru (RSI), Keinginan untuk merekomendasikan universitas kepada orang lain (REKOM), Rasa Bangga dengan Almamater (RB).

3. Reputasi Universitas (RE)

Emotional Appeal (EA), Citra Universitas (CU), Pelayanan Prima (PP), Workplace Environtment (WE), Product and Services (PS), Vision and Leadership (VL).

Analisis statistik deskriptif adalah hasil analisa berupa gambaran dalam menentukan maksimum, minimum, mean, dan standar deviasi berdasarkan jawaban yang diberikan responden menggunakan pengukuran tertentu untuk setiap variabel. Berdasarkan gambaran statistik deskriptif pada Tabel 1, terlihat bahwa pertanyaan untuk masing-masing indikator memiliki nilai Minimum 1 dan nilai Maksimum 5 dengan skala Likert, kecuali untuk indikator Vision and Leadership (VL) yang dari 425 responden tidak ada yang menjawab dengan pilihan nilai 1. Jika dilihat dari nilai Mean setiap indikator, semua indikator memuat nilai Mean lebih besar dari 3, sehingga dapat mendeskripsikan bahwa mayoritas responden menyetujui dari pertanyaan berdasarkan indikator yang disebarkan pada penelitian ini.

Tabel 1. Statistik Deskriptif

\begin{tabular}{llllll}
\hline & N & Min & Max & Mean & $\begin{array}{l}\text { Std. } \\
\text { Deviation }\end{array}$ \\
\hline AC & 425 & 1 & 5 & 4.004725 & 0.830733 \\
RC & 425 & 1 & 5 & 4.149033 & 0.823077 \\
FUC & 425 & 1 & 5 & 4.058833 & 0.84789 \\
PC & 425 & 1 & 5 & 3.868267 & 0.900883 \\
KIU & 425 & 1 & 5 & 3.910567 & 0.949627 \\
KIMS & 425 & 1 & 5 & 3.7 & 1.035028 \\
RSI & 425 & 1 & 5 & 4.0329 & 0.879505 \\
REKOM & 425 & 1 & 5 & 4.0557 & 0.93563 \\
RB & 425 & 1 & 5 & 4.159233 & 0.93998 \\
EA & 425 & 1 & 5 & 4.021167 & 0.92632 \\
CU & 425 & 1 & 5 & 4.163525 & 0.82972 \\
PP & 425 & 1 & 5 & 3.9160667 & 0.8345667 \\
WE & 425 & 1 & 5 & 4.0298 & 0.79946333 \\
PS & 425 & 1 & 5 & 4.086475 & 0.810993 \\
VL & 425 & 2 & 5 & 4.152133 & 0.763897 \\
\hline
\end{tabular}




\section{Hasil Uji Kualitas Data}

\section{Hasil Uji Validitas KSMU (Konten Sosial Media Universitas)}

Pengujian validitas indicator pada masing-masing variable dikatakan valid apabila hasil yang didapat melebihi dari angka 0,5. Data dari Tabel 2, setiap indikator pada variabel KSMU setelah diuji nilai validitasnya ternyata nilai hasil melebihi angka 0.5. Hal ini menunjukkan bahwa kuesioner, tepatnya pertanyaan setiap indikator pada variabel KSMU di penelitian ini sudah tepat dan sah.

Tabel 2. Hasil Uji Variabel KSMU

\begin{tabular}{llll}
\hline Indikator & Tanda & Hasil & Komplimen \\
\hline \multirow{4}{*}{ Advantageous } & AC1_1 & .592 & Valid \\
Campaign & AC1_2 & .687 & Valid \\
& AC1_3 & .513 & Valid \\
\multirow{4}{*}{ Relevant Content } & AC1_4 & .790 & Valid \\
& RC1_1 & .791 & Valid \\
Frequently & RC1_2 & .845 & Valid \\
Content & Up1_3 & .759 & Valid \\
& FUC1_1 & .766 & Valid \\
Popular Content & FUC1_2 & .698 & Valid \\
& FUC1_3 & .796 & Valid \\
& PC1_1 & .819 & Valid \\
& PC1_2 & .821 & Valid \\
\hline
\end{tabular}

\section{Hasil Uji Validitas LM (Loyalitas Mahasiswa)}

Pengujian validitas indikator pada masing masing variable dikatakan valid apabila hasil yang didapat melebihi dari angka 0.5. seperti Tabel 3. Pada data yang disajikan pada Tabel 3, setiap indikator pada variabel $\mathbf{L M}$ setelah diuji validitasnya ternyata memiliki nilai hasil melebihi 0,5. Hal ini menunjukkan bahwa kuesioner yang dilakukan pada penelitian ini, khususnya untuk pertanyaan dengan ruang lingkup indikator variabel LM dinyatakan valid untuk digunakan.

Tabel 3. Hasil Uji Variabel LM

\begin{tabular}{llll}
\hline Indikator & Tanda & Hasil & Komplimen \\
\hline \multirow{2}{*}{ Keinginan untuk berinteraksi dengan } & KIU2_1 & .796 & Valid \\
Universitas & KIU2_2 & .731 & Valid \\
& KIU2_3 & .744 & Valid \\
Keinginan untuk berinteraksi dengan & KIMS2_1 & .744 & Valid \\
Universitas menggunakan Media & KIMS2_2 & .761 & Valid \\
Sosial & KIMS2_3 & .748 & Valid \\
& KIMS2_4 & .803 & Valid \\
Rasa ingin tahu Informasi terbaru & RSI2_1 & .803 & Valid \\
& RSI2_2 & .598 & Valid \\
Keinginan untuk merekomendasi & REKOM2_1 & .743 & Valid \\
Universitas kepada orang lain & REKOM2_2 & .789 & Valid \\
& REKOM2_3 & .732 & Valid \\
Rasa Bangga dengan Almamater & RB2_1 & .730 & Valid \\
& RB2_2 & .768 & Valid \\
& RB2_3 & .792 & Valid \\
\hline
\end{tabular}




\section{Hasil Uji Validitas Reputasi Universitas (RE)}

Pengujian validitas indicator pada masing masing variable dikatakan valid apabila hasil yang didapat melebihi dari angka 0,5. Indikator Emotional Appeal (EA) dengan angka .805 hingga .829 maka dapat disimpulkan bahwa setiap pertanyaan dalam indikator Emotional Appeal (EA) termasuk valid karena memenuhi syarat minimum dengan nilai menyentuh angka 0.5. indikator Citra Universitas (CU) dengan nilai hasil sebesar 0.640 sampai dengan 0.780 terbukti bahwa pertanyaan dalam indikator Citra Universitas (CU) termasuk valid karena memenuhi syarat minimum dengan nilai menyentuh angka 0.5. indikator Pelayanan Prima (PP) dengan nilai hasil sebesar 0.659 sampai dengan 0.711 sehingga menunjukkan bahwa setiap pertanyaan dalam indikator Pelayanan Prima (PP) termasuk valid karena memenuhi syarat minimum dengan nilai menyentuh angka 0.5. indikator Workplace Environment (WE) mencapai angka 0.507 sampai dengan 0.797 sehingga ditarik kesimpulan bahwa setiap pertanyaan dalam indikator Workplace Environment (WE) termasuk valid karena telah memenuhi syarat minimum dengan nilai menyentuh angka 0.5 . indikator Product and Services (PS) dengan nilai hasil sebesar 0.752 sampai dengan 0.833 sehingga dapat disimpulkan bahwa setiap pertanyaan dalam indikator Product and Services (PS) termasuk valid karena memenuhi syarat dengan mencapai angka 0.5. indikator Vision and Leadership (VL) dengan nilai hasil sebesar 0.707 sampai dengan 0.791 sehingga dapat disimpulkan bahwa setiap pertanyaan dalam indikator Vision and Leadership (VL) termasuk valid karena memenuhi syarat minimum dengan nilai menyentuh angka 0.5 .

\section{Hasil Uji Reliabilitas}

Pengujian reliabilitas ini diterapkan untuk menghitung tingkat kepahaman objek penelitian, dalam hal ini jawaban responden pada kuesioner yang diberikan pada variabel dalam penelitian ini melalui metode perhitungan Cronbach Alpha dengan syarat nilai Cronbach Alphanya harus lebih besar dari 0,6. Dari data yang disajikan pada tabel 5, setiap indikator pada ketiga variabel menunjukkan nilai Cronbach Alpha melebihi angka 0,6. Hal ini menyatakan bahwa setiap indikator pada ketiga variabel tersebut reliabel sehingga dapat dikatakan untuk pertanyaan-pertanyaan yang disampaikan dalam survei dapat dipahami dengan benar oleh responden.

\section{Hasil Uji Asumsi Klasik (Uji Heteroskedastisitas)}

Hasil Uji Heteroskedastisitas ditampilkan dalam menilai similaritas yang ada antar variabel, pada penelitian ini digunakan diagram Scatterplot dengan gambar 1. Berdasarkan hasil uji yang dimodelkan pada gambar 1, menunjukkan adanya pola tertentu atau scatterplot yang tersebar dengan titik sembarang sehingga dapat dinyatakan bahwa tidak adanya data yang memiliki gejala heteroskedastisitas.



Gambar 1. Hasil Uji Heteroskedastisitas 
Tabel 5. Hasil Uji Reliabilitas

\begin{tabular}{llll}
\hline \multicolumn{2}{c}{ Variable - Indikator } & Cronbach Alpha & Simpulan \\
\hline 1. & KSMU & & \\
a. & AC & .714 & reliabel \\
b. & RC & .836 & reliabel \\
c. & FUC & .768 & reliabel \\
d. & PC & .887 & reliabel \\
2. & LM & & \\
a. & KIU & .913 & reliabel \\
b. & KIMS & .884 & reliabel \\
c. & RSI & .695 & reliabel \\
d. & REKOM & .844 & reliabel \\
e. & RB & .896 & reliabel \\
3. & RE & & \\
a. & EA & .925 & reliabel \\
b. & CU & .861 & reliabel \\
c. & PP & .828 & reliabel \\
d. & WE & .678 & reliabel \\
e. & PS & .877 & reliabel \\
f. & VL & .860 & reliabel \\
\hline
\end{tabular}

\section{Hasil Uji F}

Berdasarkan data pada tabel 6, dapat dilihat nilai signifikansi pada variable bebas berpengaruh secara signifikan pada variable terikat dengan hasil nilai $0,000<0,05$ dan berdasarkan nilai $\mathrm{F}$ hitung dan $\mathrm{F}$ tabel, didapatkan nilai $\mathrm{F}$ hitung yaitu 678.520 lebih besar dari nilai $\mathrm{F}$ table yang didapat sebesar 3,0319 (678.520> 3,0319) maka dari itu dapat ditarik kesimpulan bahwa pada variabel Konten Sosial Media Universitas (KSMU) dan Loyalitas Mahasiswa (LM) menujukkan adanya pengaruh yang signifikan terhadap variabel Reputasi Universitas (RE).

Tabel 6. Hasil Uji F

\begin{tabular}{ccccccc}
\hline & Model & Sum of Squares & df & Mean Square & F & Sig. \\
\hline \multirow{4}{*}{1} & Regression & 93.206 & 2 & 46.603 & 678.520 & $.000^{\mathrm{b}}$ \\
& Residual & 26.924 & 392 & .069 & & \\
& Total & 120.129 & 394 & & & \\
\hline
\end{tabular}

\section{Hasil Uji t}

Pada tahapan penelitian ini menggunakan uji-t yang terlihat pada tabel 7 . Hasil ini menggunakan angka signifikansi senilai 5\% (0,05). Jika angka Sig sebesar $\leq 0,05$ atau $\mathrm{T}$ hitung > T tabel $(1,968)$ dapat disimpulkan bahwa adanya hubungan yang signifikan pada variable bebas dan variable terikat. Sehingga dapat ditarik kesimpulan bahwa:

Hipotesis untuk Tujuan 1

Ho: Konten Media Sosial Universitas tidak memiliki pengaruh terhadap reputasi universitas. (Ditolak)

Ha: Konten Media Sosial Universitas memiliki pengaruh terhadap reputasi universitas.

\section{(Diterima)}

Hipotesis untuk Tujuan 2

Ho: Loyalitas Mahasiswa tidak berpengaruh pada reputasi universitas di lingkungan sosial. (Ditolak) 
Ha: Loyalitas Mahasiswa berpengaruh pada reputasi universitas di lingkungan sosial. (Diterima)

\begin{tabular}{llccccc}
\hline Model & \multicolumn{2}{c}{$\begin{array}{c}\text { Unstandardized } \\
\text { Coefficients }\end{array}$} & $\begin{array}{c}\text { Standardized } \\
\text { Coefficients } \\
\text { Beta }\end{array}$ & t & Sig. \\
& B & Std. Error & Beta & \\
\hline \multirow{2}{*}{$\mathbf{1}$} & (Constant) & .897 & .096 & & 9.309 & .000 \\
& KSMU_AVG & .159 & .047 & .164 & 3.394 & .001 \\
& LM_AVG & .640 & .042 & .735 & 15.252 & .000 \\
\hline
\end{tabular}

\section{Hasil Uji Koefisien Determinasi}

Uji Koefisien Determinasi diterapkan guna mengetahui nilai besaran pengaruh variable bebas terhadap variable terkait apakah terdapat faktor diluar model dipengaruhi oleh kedua variable tersebut. Pada tabel 8 menunjukkan bahwa, nilai $\mathrm{R}$ sebesar $88.1 \%$ yang berarti variabel bebas mampu menjelaskan variabel terikat sebesar 88.1\%. Untuk Angka $\mathrm{R}$ square sebesar 77,6\% mencermikan bahwa variabel terikat mampu menjelaskan variabel bebas senilai $77,6 \%$ dan $22,4 \%$ merupakan faktor variabel lain diluar dari model regresi pada penelitian ini.

Tabel 8. Hasil Uji Koefisien Determinasi

\begin{tabular}{cccccc}
\hline Model & $\mathbf{R}$ & R Square & $\begin{array}{c}\text { Adjusted R } \\
\text { Square }\end{array}$ & $\begin{array}{c}\text { Std. Error of the } \\
\text { Estimate }\end{array}$ & $\begin{array}{c}\text { Durbin- } \\
\text { Watson }\end{array}$ \\
\hline $\mathbf{1}$ & $.881^{\mathrm{a}}$ & .776 & .775 & .26207 & 2.119 \\
\hline
\end{tabular}

\section{Pembahasan}

Berdasarkan hasil yang didapat dari responden yang mengisi kuesioner bahwa untuk mayoritas mahasiswa yang mengisi berasal dari Universitas Internasional Batam sebesar 72\% atau sebanyak 285 orang mahasiswa yang mengisi, pada urutan kedua mahasiswa universitas batam sebesar $10 \%$ atau sebanyak 40 orang mahasiswa yang mengisi, selanjutnya adalah Universitas Ibnu Sina dengan sebesar 6\% atau sebanyak 24 orang mahasiswa yang mengisi kuesioner dan untuk sisanya berasal dari beberapa institusi Pendidikan tinggi yang berada di Kota Batam. data responden berdasarkan semester mahasiswa yang mengisi kuesioner yang disebar, mahasiswa semester 5 sebanyak 252 (dua ratus lima puluh dua) mahasiswa atau 64\% yang mengisi kuesioner penelitian ini, mahasiswa semester 3 sebanyak 64 (enam puluh empat) mahasiswa atau $16 \%$ yang mengisi kuesioner penelitian ini, mahasiswa semester 7 sebanyak 34 (tiga puluh empat) mahasiswa atau 9\% yang mengisi kuesioner penelitian ini dan selanjutnya adalah semester-semester lainnya. Berdasarkan usia yang paling banyak mengisi adalah usia 20 tahun sebesar 56\% responden berusia tersebut ini membuktikan bahwa memang yang mengisi kuesioner yang disebar adalah mahasiswa aktif karena rentan usianya adalah usia mahasiswa. Asal prodi mahasiswa yang paling banyak mengisi kuesioner yang diberikan adalah prodi system informasi dengan sebesar 53\% atau sebanyak 210 orang mahasiswa. Dari kuesioner yang dibagikan didapat data bahwa yang mengisi kuesioner adalah mahasiswa yang sering menggunakan media social Instagram, untuk perangkat yang digunakan paling banyak mengunakan telepon pintarnya dalam mengakses Instagram, fitur yang paling sering mahasiswa gunakan pada Instagram adalah fitur Stories, serta fitur yang paling sering mahasiswa lihat dan akses adalah fitur Stories, mahasiswa rata-rata menghabiskan waktu dalam menggunakan media social Instagram selama 2 jam s.d 4 jam dalam sehari, dengan temuan-temuan ini dapat disimpulkan bahwa yang mengisi kuesioner ini sudah tepat pada sasaran. 
Peran Konten Sosial Media Universitas (KSMU) terhadap Reputasi Universitas $\left(\mathrm{X}_{1}\right)$. Konten Sosial Media Universitas memiliki peranan penting dalam meningkatkan Reputasi Universitas, hal ini ditunjukan pada hasil uji hipotesis yang menerima pernyataan bahwa Konten Media Sosial Universitas memiliki pengaruh terhadap reputasi universitas. Sehingga dari pihak Universitas alangkah baiknya lebih meningkatkan lagi keaktifan dalam menyebarkan informasi penting dan menarik mengenai program yang dijalankan pada Universitas melalui Sosial Media yang digunakan agar reputasi universitas tetap terjaga dan dicap baik. Hasil ini senada dengan hasil penelitian dari (Erdoğmuş \& Çiçek, 2012) yang berjudul The impact of social media marketing on brand loyalty Penelitian ini mengatakan bahwa marketing melalui media sosial bisa dikatakan sebagai alat yang dapat membangun hubungan dan citra positif suatu merek dengan konsumen. Hasil dari penelitian ini membuktikan bahwa konten yang menguntungkan yang terdapat pada sosial media sangat mendorong brand reputation. Maka dari itu suatu perguruan tinggi atau universitas harus selalu memberikan konten dan menyebarkan informasi kepada seluruh pengguna dan pengikutnya di media sosial agar reputasi universitas tersebut akan terus meningkat seiring dengan interaksi yang terjalin pada media sosial.

Peran Loyalitas Mahasiswa (LM) terhadap Reputasi Universitas $\left(\mathrm{X}_{2}\right)$

Loyalitas Mahasiswa memiliki pengaruh yang signifikan terhadap Reputasi Universitas, hal ini disimpulkan dari hasil uji hipotesis variabel LM yang menerima hipotesis bahwa Loyalitas Mahasiswa berpengaruh pada reputasi universitas di lingkungan sosial. Sehingga loyalitas mahasiswa harus dijunjung tinggi oleh Universitas dengan sering mengadakan program belajar yang lebih menarik, meningkatkan pelayanan Universitas, dan menunjukan reliabilitas para dosen sehingga dapat dikagumi dan dijadikan contoh oleh para mahasiswa hasil ini senada dengan hasil penelitian dari (Ariadi \& Sosial, 2014) judul penelitian Pengaruh Media Sosial Twitter Terhadap Loyalitas Merek INDOSAT IM3 penelitian ini berkesimpulan bahwa terdapat pengaruh yang positif antara konten yang relevan di media sosial dengan loyalitas merek. Dengan kata lain, dapat dikatakan bahwa konten yang relevan dapat meningkatkan loyalitas merek. Terdapat pengaruh yang positif antara konten di media sosial twitter dengan loyalitas merek pada produk. Artinya kenaikan konten di media sosial twitter akan menyebabkan loyalitas merek. Maka dari itu universitas harus terus menumbuhkan rasa loyalitas mahasiswa dengan cara selalu menjalin hubungan, memberikan pelayanan, dan program yang baik agar mahasiswa tetap merasa bangga dan loyal kepada universitas dengan cara ini reputasi universitas yang bersangkutanpun akan semakin meningkat.

\section{SIMPULAN}

Hasil penelitian ini menunjukkan bahwa variabel yang berpengaruh atas reputasi universitas yaitu variabel konten media social universitas dan loyalitas mahasiswa dengan ini maka universitas harus memberikan konten yang bermanfaat, informatif, dan kreatif guna menarik mahasiswa untuk melihat media social universitas serta mau berinteraksi dengan universitas memalui media social universitas. Selain itu loyalitas mahasiswa juga harus tetap universitas pertahankan dengan memberikan pelayanan yang optimal, dan memberikan kualitas perkuliahan yang baik pula serta menumbuhkan rasa bahwa kampus adalah rumah kedua dari mahasiswa dengan seperti ini loyalitas mahasiswa akan meningkat.

\section{REFERENSI}

Apriananta, Y. J., \& Wijaya, L. S. (2018). Penggunaan Website Dan Media Sosial Dalam Membangun Citra Positif Perguruan Tinggi. Jurnal Komunikatif, 7(2), 187-209. https://doi.org/10.33508/jk.v7i2.1750

Ariadi, S., \& Sosial, P. M. (2014). Pengaruh Media Sosial TWITTER Terhadap Loyalitas 
Merek INDOSAT IM3. Jurnal Ilmu Manajemen Universitas Negeri Surabaya, 2(4), 1380-1392.

Erdoğmuş, İ. E., \& Çiçek, M. (2012). The Impact of Social Media Marketing on Brand Loyalty. Procedia - Social and Behavioral Sciences, 58, 1353-1360. https://doi.org/10.1016/j.sbspro.2012.09.1119

Febriyanti, D. F., \& Ismatulloh, K. (2019). Pengaruh Model Pembelajaran Group Investigasi Berbantuan Media Flashcard Terhadap Minat Dan Hasil Belajar. Edumatic: Jurnal Pendidikan Informatika, 3(2), 53-60.

Husda, N. E. (2019). Analisis Customer Value Dalam Memediasi Pengaruh Sistem Informasi Manajemen Terhadap Reputasi Universitas Swasta Di Kota Batam. Jurnal Manajemen Pemasaran, 13(2), 61-68. https://doi.org/10.9744/pemasaran.13.2.61-68

Izzati, M., \& Kuswanto, H. (2019). Pengaruh model pembelajaran blanded learning berbantuan kahoot terhadap motivasi dan kemandirian siswa. EDUMATIC: Jurnal Pendidikan Informatika, 3(2), 68-75.

Limongi, R., Santos, D., \& Almeida, M. S. De. (2016). Does social media matter for post typology? Impact of post content on Facebook and Instagram metrics Article information : (June). https://doi.org/10.1108/OIR-06-2015-0176

Lisettede Vries, Gensler;, S., \& S.H., L. P. (2012). Popularity of Brand Posts on Brand Fan Pages: An Investigation of the Effects of Social Media. Journal of Interactive Marketing, 83-91. https://doi.org/https://doi.org/10.1016/j.intmar.2012.01.003

Luarn, P., \& Chiu, Y. (2015). Influence of Facebook brand-page posts on online engagement. (December). https://doi.org/10.1108/OIR-01-2015-0029

Munandar, A. (2017). Analisis Regresi Data Panel Pada Pertumbuhan Ekonomi Di NegaraNegara Asia. Jurnal Ilmiah Ekonomi Global Masa Kini, 8(1), 59-67.

Nurbani, N., \& Permana, R. (2020). Efektivitas E-Portofolio Berbantuan Edmodo Terhadap Keaktifan Belajar dan Kreativitas Mahasiswa Pada Matakuliah Desain Grafis. Edumatic: Jurnal Pendidikan Informatika, 4(2), 129-135.

Nuryanto, H. (2012). Sejarah Perkembangan Teknologi dan Komunikasi (1st ed.). Jakarta: Balai Pustaka.

Ryan;, K. S., \& Zabin, J. (2010). Gleansight: Social Media Marketing. Gleanster LCC, 1-21.

Santoso, A., Baihaqi, I., \& Persada, S. (2017). Pengaruh Konten Post Instagram terhadap Online Engagement: Studi Kasus pada Lima Merek Pakaian Wanita. Jurnal Sains Dan Seni ITS, 6(1), 50-54.

Sartikah, S., Razati, G., \& Utama, R. D. H. (2019). Peran Media Sosial Dalam Memperkuat Loyalitas Pada Merek. Strategic: Jurnal Pendidikan Manajemen Bisnis, 18(1), 28-36. https://doi.org/10.17509/strategic.v18i1.17588

Sriningsih, M., Hatidja, D., \& Prang, J. D. (2018). Penanganan Multikolinearitas dengan Menggunakan Analisis Regresi Komponen Utama pada Kasus Impor Beras di Provinsi Sulut. Jurnal Ilmiah Sains, 18(1), 18-24.

Sugiyono. (2018). Metode Penelitian Kuantitatif, Kualitatif dan R\&D. Bandung: Alfabeta.

Uska, M. Z. (2017). Analisis Penerimaan Digital Library Menggunakan Technology Acceptance Model (TAM) di Universitas Hamzanwadi. Edumatic: Jurnal Pendidikan Informatika, 1(1), 1-10.

Uska, M. Z., \& Wirasasmita, R. H. (2018). Analisis Teknologi Smartphone dalam Mendukung Kegiatan Akademis di Universitas Hamzanwadi Menggunakan Technology Acceptance Model. Edumatic: Jurnal Pendidikan Informatika, 2(2), 51-60. 